\title{
Empoderamiento estudiantil universitario de la diversidad sexual en el Departamento del Atlántico, Colombia
}

\author{
Trabajo Resultados de Investigación \\ Ligia Cantillo-Barrios ${ }^{14}$
}

\section{Introducción}

Los estudios sobre diversidad sexual son recientes y han logrado identificar y entrever las distintas manifestaciones de la sexualidad humana, Cantillo (2016) afirma: "La sexualidad humana se afianza y proyecta como heterosexual y heteronormatizada por la actividad erótica de las personas bajo el paraguas de la heterosexualidad como patrón ideal de sensualidad" (p. 96). La misma es tan variada como la misma circunstancia que atraviesan a cada persona desde su nacimiento, durante todo el transcurso de su vida y hasta la muerte.

Por su parte, Careaga (2004), señala: que a través de los estudios sobre diversidad sexual se ha posibilitado suprimir la usanza ofensiva que circulaba cotidianamente en el entramado social contra esa población, convirtiéndose en escenarios para la deliberación sobre las diferentes manifestaciones de como las personas expresan y disfrutan su sexualidad. Asimismo, Weeks (1998) afirma: la diversidad involucra las sexualidades "plurales, polimorfas y placenteras" como homosexualidad, lesbianismo, bisexualidad y transgénero (travestis y transexuales).

${ }^{14}$ Socióloga, Especialista en Género Planeación y Desarrollo y Maestría en Estudios Políticos y Económicos. Coordinadora de la Maestría en Estudios de Género y Violencia Intrafamiliar. Docente- investigadora, Integrante del Grupo de Investigación: Goffman del programa de sociologia de la Universidad del Atlántico, Barranquilla, Colombia. Contacto: ligiacantillo@uniatlantico.edu.co 
La sexualidad humana es única, irrepetible, con rasgos y particularidades intrínsecas que hacen del cuerpo un ser sexuado inserto en un contexto sociocultural e histórico específico. Esta se construye en el entramado social y cultural que la produce, trasmite y habitúa de generación en generación a través del proceso de socialización y que establece la heterosexualidad como modelo estandarizado de lo erótico y afectivo y así, lo que sale de esa norma es considerado "anormal". De esta manera, la homosexualidad al ser disidente no es normatizada socialmente como natural y por ende no es “normal". Lagarde (2005), señala: "la sexualidad específicamente humana (...) es uno de los espacios privilegiados de la sanción, del tabú, de la obligatoriedad y de la transgresión" (p. 194).

Las investigaciones sobre diversidad sexual surgen en el seno del feminismo a partir de las reflexiones lésbico, gay y queer, como una forma de analizar, visibilizar, sensibilizar e intervenir la situación de exclusión y discriminación que vive este grupo social por estar fuera de lo heteronormativo. Es decir, que esta trasgresión sexual es fortalecida a través del abordaje conceptual sobre el tema que da cuenta de esa realidad sociohistórica. En este sentido, Careaga (2004), asevera: que la diversidad sexual se derivó de los estudios de gays y lesbianas y posteriormente de los estudios queer.

En la actualidad, alrededor de los estudios de diversidad sexual se ha construido un campo teórico interdisciplinar que condensa la multiplicidad de saberes y enfoques para su abordaje. Además, se ha identificado la situación de avances y limitaciones que viven lesbianas, gays, transexuales, bisexuales e intersexuales con relación a sus derechos humanos y las formas que buscan para reivindicarlos y así, puedan ejercer su ciudadanía plena, como sujetos de derechos. Vera-Gamboa (1998) confirma: que los mismos permitieron reflexionar sobre las prácticas sexuales positivas y negativas, identificándose, lo bueno y malo de la estigmatización que señalan las consideraciones de la sexualidad humana como prohibición.

La diversidad sexual, en torno a la reivindicación de sus derechos humanos, realiza a nivel internacional, nacional y local una serie de acciones de hecho y derecho desde lo individual y colectivo. Esto ha permitido visibilizar y sensibilizar el tema y de esta forma, se han generado aceptación para su inclusión. Cantillo (2013) señala: "la sexualidad alternativa se ha 
ido visibilizando más, cada vez gana más espacio y parece enfrentarse a menos restricciones" (p. 26). Entre ellas, cabildeo, marchas, plantones y capacitación, generando un movimiento social de los más representativos de este momento histórico. Evidenciándose en una sucesión de manifestaciones en diversos espacios de la cotidianidad, entre las experiencias específicas de organización se señalan las surgidas en tres universidades ubicadas en el Departamento del Atlántico: la Universidad del Atlántico ${ }^{15}$, la Universidad del Norte ${ }^{16}$ y la Universidad Autónoma del Caribe ${ }^{17}$, las cuales son inspiradas por la juventud estudiantil universitaria y denominadas como: Uniatlántico Diverso, Uninorte Diverso y UAC-Pride ${ }^{18}$.

\section{Generalidades históricas}

La diversidad sexual ${ }^{19}$ ha estado presente en la historia de la humanidad. La forma como se ha presentado y asumido su aceptación o rechazo ("bueno" o "malo") por parte de la sociedad y de la misma población diversa está en correspondencia con las dinámicas sociales de cada momento sociohistórico, cultural y político. Aunque, independiente de lo uno o lo otro, la comunidad de lesbianas, gays, transexuales, bisexuales e intersexuales, LGTBI, son una realidad histórica y social de la humanidad, indistintamente de si la sociedad la aprueba o rechaza, su existencia ha permanecido en el tiempo y en todos los espacios de la cotidianidad sin aprobación o no

${ }^{15}$ Es una institución pública de educación superior en Colombia. Adscrito a la Gobernación del Atlántico, ubicada en el municipio de Puerto Colombia, Departamento del Atlántico.

${ }^{16}$ La Fundación Universidad del Norte es una institución privada de educación superior colombiana con sede en el municipio de Puerto Colombia. Cuenta con la "acreditación institucional de Alta Calidad".

${ }^{17}$ Universidad Autónoma del Caribe es un centro de educación superior, del sector privado, está ubicada en la ciudad de Barranquilla, Colombia.

${ }^{18}$ Estos son grupos estudiantiles de diversidad sexual de diferentes programas que se han organizado por la defensa de sus derechos en tres universidades del departamento del Atlántico (Atlántico, Norte y Autónoma). Tienen el apoyo institucional, de algunos estudiantes heterosexuales y docentes para realizar acciones de visibilización y denuncias como comunidad diversa.

${ }^{19}$ Se define nombrar diversidad sexual a la población de lesbianas, gays, transexuales, bisexuales e intersexuales como una forma de mayor inclusión de la variedad de denominaciones que suelen hacerse sobre dicha población. 
aprobación. Fausto-Sterling (2006) afirma: que la homosexualidad siempre ha formado parte de la sociedad, por tanto, se debe aceptar como fracción de la misma y de esta forma, deberíamos permitir que acabe de incorporarse en la cultura preferentemente. La misma, autora (2006), expresa: "la sexualidad es un hecho somático creado por un efecto cultural” (p.37).

La sociedad ante la disidencia heteronormativa asume tres actitudes: aceptación, rechazo o indiferencia. Quienes asumen la primera, interactúan con la misma sin ningún tipo de agresión o discriminación. Mientras que la segunda, lo expresan con una sucesión de fobias lacerantes de la dignidad humana a esta comunidad, la cual la manifiestan desde la sanción familiar, social, pasando por condenas de prisión, cadena perpetua y hasta la muerte y la tercera, tienen una actitud indiferente frente al hecho. De esta manera, la población disidente asume generalmente la cautela y el ocultamiento como garantía para su seguridad física y emocional. Aunque, existen quienes han trasgredido la "norma heterosexual" pese a la represalia y el precepto social.

La trasgresión realizada por la diversidad sexual les ha posibilitado ganar resistencia, empoderamiento y resiliencia para asumirse como sujetos de derecho en una sociedad que hace de la diferencia exclusión y discriminación. De esta manera, se han hecho visibles y han pasado del espacio privado al espacio público, y en lo público han generado organización, movilización e incursión como un movimiento social de trascendencia internacional.

Desde esta perspectiva, la trasgresión les ha permitido organizar un movimiento social que reclama la inclusión y el reconocimiento de ser sujetos y sujetas de derechos desde la disidencia. Esto se hizo posible por las trasformaciones de las dinámicas sociales que reconocen garantías de derechos a toda la población sin discriminación. Esta comunidad tuvo como punto de apoyo al movimiento feminista que promocionó la revolución sexual y las teorías de género. Igualmente, la aparición de los procesos globalizantes generadores de nuevos espacios para la interrelación humana, más democráticos e incluyentes. Estos sucesos han sido claves para reivindicar sus derechos y el reconocimiento de sujetos plenos. De esta forma, a través de su movimiento social han reivindicado la no discriminación que socialmente se les adjudica por no estar en la heterosexualidad. 
Esta reivindicación por los derechos de la disidencia sexual se instruye a finales del Siglo XIX por la iniciativa de activistas, quienes inicialmente lo hicieron en forma individuales y luego desde lo colectivo, estos se atrevieron a trasgredir la norma heteronormativa en lo público. Los primeros intentos fueron generados por algunos grupos en forma aislada, eran de carácter humanista con el objetivo de lograr la eliminación de todas las formas exclusión que los solía presentar como personas con algún tipo de "desviación social", de esta forma, estaban identificados como: "perversas"; "pecaminosas"; "anormales"; "enfermas", "degeneradas" y "delincuentes". Giddens (2008) asevera: que gran parte de la literatura clínica lo asumía como trastornos.

Las distintas iniciativas y prácticas por la exigibilidad de derechos homosexuales en varias partes de Europa, Estados Unidos y otros lugares del planeta fueron el nido que acunó el estallido de su resistencia histórica en la ciudad de Nueva York (junio 28 de 1969), Según Panadero (s.f), cuando un grupo de gays resisten a la invasión policial del bar Stonewall Inn (situado en la calle Christopher de Greenwich Village). La oposición se realizó con marchas y enfrentamiento a las fuerzas del orden público, esta se mantuvo durante varios días. Este hecho se convirtió en el hito histórico del origen del movimiento homosexual a nivel mundial. Fortaleciéndose con la celebración del año siguiente de la "semana del orgullo gay".

Este hito histórico fue la llama que encendió, masificó y logro que el movimiento social de la diversidad sexual se posesionara en el mundo como uno de los más representativos de este siglo. Extendiéndose luego en todo el planeta con una variedad de formas organizativas, demandas de exigibilidad y reconocimiento de sus derechos sociales, políticos, culturales, jurídicos, económicos y en especial, su sexualidad no heteronormativa, como una evidencia fehaciente de su presencia y su deseo de existir plenamente como sujetos de derechos en un mundo democratizado.

En América Latina inicialmente surge en Argentina, Brasil y México, expandiéndose después en todo el territorio y llega a Colombia. De esta forma, el movimiento de diversidad sexual se ha diseminado en todo el país y con mayor presencia en las capitales de los centros urbanos donde el ejercicio de la práctica no heterosexual tiene mayor impacto de acción, visibilización, sensibilización y por tanto, de intervención social. 
En Colombia, el movimiento se inicia por un grupo pequeño de hombres de nivel socioeconómico alto, quienes actuaban en la clandestinidad. $\mathrm{Su}$ objetivo era buscar espacios de homosocialización, con este fin crearon los primeros bares gays. De esta forma, se fue generando y ampliando el encuentro, reconocimiento y autoreconocimiento de la comunidad homosexuales, dándose así, los inicios para su organización social. Según, Velandia (2007), en los años setenta (70) León Zuleta, en la ciudad de Medellín, organiza un grupo que se extendió a Bogotá por el Manuel Velandia, llamado Movimiento por la Liberación Homosexual. El mismo generó varias acciones: Primera marcha gay y la primera publicación gay en el país Revista, Ventana Gay (fundada en 1980).

Además, crearon según, el mismo Velandia (2007), el Grupo de Estudio y Liberación Gay (GEL). Estos espacios eran casi de exclusividad para hombres. Luego surgieron, una variedad de nuevas organizaciones donde ya se incluyen las mujeres lésbicas como: el movimiento lésbico Triángulo Negro: Mujeres al Borde; Colectivo Lésbico y Fundación Mujeres de Ébano, entre otras. También, Planeta Paz, nace en 2000 como promotora de los procesos de paz en Colombia y en el 2003 Colombia Diversa, organización no Gubernamental, que reivindica los derechos de la población LGBT y un centenar de organizaciones de distintas expresiones y sitios del país, donde se promueven la no discriminación de lesbianas, gays, transexuales, bisexuales e intersexuales donde quieran que reclaman sus derechos humanos.

El accionar individual y colectivo de diversidad sexual en Colombia posibilitó fundar un movimiento a escala del país de visibilización, sensibilización e intervención social de gran trascendencia nacional. Generador de una variedad de acciones, entre los logros se nombran: Construir un movimiento social desde lo local con impacto en el país, incidiendo en la promoción de campañas en toda Colombia sobre $\mathrm{VIH}^{20} / \mathrm{SIDA}^{21}$ y la no homofobia, entre otras. La celebración oficial y masificada del Día del Or-

${ }^{20} \mathrm{O}$ virus de la inmunodeficiencia humana es un microorganismo que ataca el sistema inmunológico de las personas

${ }^{21}$ Es el síndrome de inmunodeficiencia adquirida. Se considera la etapa más avanzada del proceso que inicia con la infección por el VIH. Esta enfermedad era considerada en su momento como una enfermedad exclusiva de homosexuales. 
gullo Gay (28 de junio). La Primera Convención Nacional de Gays y Lesbianas (realizada en el año 2000). La inclusión jurídica sobre los derechos humanos específicos de la diversidad sexual en Colombia ${ }^{22}$ : La inclusión del tema en las agendas de las entidades del Estado, privadas y Organizaciones no Gubernamentales, ONG. La movilización social de hecho y de derechos como espacio para exigibilidad de derechos y la visibilización y sensibilización social.

La movilización por los derechos humanos de la diversidad sexual en la región Caribe impacta a través de varias acciones individuales y colectivas. Convirtiéndose en un avance para la visibilización, sensibilización e inclusión del tema en las agendas públicas, privadas y académicas. Una es Caribe Afirmativo $^{23}$. Su dirigente, Wilson Castañeda, afirma que: "en la región Caribe, se han presentado cuatro procesos claves: Uno, la creación y funcionamiento de la Mesa de Organizaciones Sociales lesbianas, gays, transexuales, bisexuales e intersexuales (LGTB) Barranquilla ${ }^{24}$, que articula y posiciona el debate público sobre diversidad sexual desde los derechos humanos. Dos, la Red Departamental de Minorías Sexuales (REDEMIS), de Magdalena, que trabaja por el fortalecimiento de personas LGBT en este Departamento y la Guajira. Tres, las iniciativas del Departamento del Cesar para que la sociedad civil partícipe en procesos de agenda pública de ese Departamento y cuatro, la Red de Estudios de Diversidad Sexual e Identidades de Género del Caribe Colombiano, liderada por Caribe Afirmativo $^{25}$, así como el Observatorio de esta organización, que hace un

${ }^{22}$ La cual garantiza la seguridad social, pensión y derecho patrimonial para las parejas igualitarias, entre otros.

${ }^{23}$ Organización civil conectada a distintos sectores sociales para el seguimiento, investigación, capacitación y formación sobre la orientación sexual, identidad de género y VIH. (fundada en 2009 en Cartagena).

${ }^{24}$ Es un espacio integrado por las organizaciones, establecimientos para público de la población LGTB y activistas en la defensa de los derechos de la comunidad diversa.

${ }^{25}$ Es una institución plural de promoción de la diversidad relacionada con diversos sectores sociales y que realiza iniciativas de seguimiento, investigación, capacitación y formación, acción pública, asesoría, consultoría, acompañamiento y promoción de los derechos humanos de la población de lesbianas, gays, bisexuales, transgénero e intersexual - LGBTI. En particular en la región Caribe. 
seguimiento de la situación de derechos humanos en la región" (Director Caribe Afirmativo1).

En el Departamento del Atlántico, y en especial el distrito de Barranquilla, a partir de la observación participante y entrevistas realizadas a la dirigencia ${ }^{26}$ del movimiento de diversidad sexual se puede señalan dos hechos de inicio para la visibilización, sensibilización y al mismo tiempo, reconocimiento de la presencia de esta comunidad en la ciudad y el Departamento: Ambos iniciados desde el micro espacio, pero con incidencia y trascendencia en la escena pública local. El primero, surge alrededor de la década del setenta (70), cuando los gays en forma individual y/o en las peluquerías de los barrios de la ciudad empiezan su labor de peluqueros y maquillistas y segundo, en la década de los 80 , algunos gays se disfrazaban con atuendos femeninos en las temporadas de los pre carnavales y carnaval, inicialmente en bares y eventos privados.

Más tarde, con el correr del tiempo, los gays peluqueros a través de sus servicios de bellezas se diseminan en toda la ciudad y en particular, se legitiman en los salones de bellezas, academia de bailes como profesores, coreografías para organizar los eventos sociales y las agrupaciones folclóricas del precarnaval y carnaval, entre otros. Por otra parte, los gays en las temporadas de precarnaval con sus disfrazases realizaban desfiles nocturnos en forma casi clandestina en algunas calles de norte de Barranquilla ${ }^{27}$, el cual anualmente se fue ampliando numéricamente y espacialmente por alguna calle de la ciudad, dándose así, inicios al Desfile Gay, liderado por Jairo Polo, entre otros.

Este evento en la actualidad está reconocido oficialmente por la A1caldía de Barranquilla con el Acta Resolutiva No. 106 del 27 de enero de 1997, y así se oficializa la creación de la Corporación Autónoma del Carnaval Gay de Barranquilla y el Atlántico ${ }^{28}$. Convirtiéndose en el desfile gay

\footnotetext{
${ }^{26}$ Entre ellos: Heriberto Mejía, Luder Fuentes y Edwin Nemes.

${ }^{27}$ Algunas veces estos desfiles eran intervenido y suspendido por la fuerza del orden que los acusaban de estar alterando el orden público, las buenas costumbres y la moral

${ }^{28}$ Es una entidad autónoma de la sociedad civil que organiza la programación de las actividades de la diversidad sexual para participar en las festividades de los precarnavales y carnavales en Barranquilla y el departamento del Atlántico.
} 
nocturno, denominado la Gran Guacherna $\mathrm{Gay}^{29}$, y el resto de las actividades que realiza la Corporación durante los pre carnavales y carnavales en Barranquilla y el resto del Departamento como eventos del carnaval. Esto se presenta como hecho cultural y sus diversas manifestaciones.

En este sentido, Cantillo (2014), afirma que estos sucesos: "se ajustan a los cambios de las nuevas dinámicas sociales con el fin de mantenerse en el tiempo y el espacio" (Pág.156). Estos dos hechos surgidos de la observación participante y entrevistas a la comunidad gay, pueden considerarse como de incidencia para la inclusión de la comunidad de diversidad sexual en la ciudad. Unos desde el espacio laboral, arreglando la presentación personal específicamente a mujeres y otro, con las manifestaciones Artísticas y culturales relacionadas con la temporada del precarnaval y carnaval que se celebra anualmente en la ciudad de Barranquilla y el resto del Departamento del Atlántico.

Las evidencias señalan que la incidencia para la acción reivindicativa por los derechos humanos de la diversidad sexual en el Departamento del Atlántico se inicia a principios del 2000. Se realizaron en forma individual y colectiva a través de organizaciones activistas, entre ellas: Fundación Arenosa Viva (FUNDARVI) ${ }^{30}$; Fundación Organización Acción Humanitaria, Fundación $\mathrm{OAH}^{31}$; el Polo de Rosa ${ }^{32}$ promovido por el Polo Democrático $^{33}$. En este se vinculó la población de diversidad sexual atlanticense.

${ }^{29}$ Este es un evento de los precarnavales de Barranquilla. Donde la diversidad sexual luciendo una variedad de disfraces desfila por una calle principal de la cuidad. Siendo observados por la población que organizada a lado y lado de la calle para apreciar el acto cultural y artístico.

${ }^{30}$ Creada en 2001 por Heriberto Mejía, inspirada en la campaña a nivel nacional del VIH/SIDA Promoción, defensa y reparación de los derechos fundamentales de las personas que viven y conviven con el virus del VIH/Sida (acciones jurídicasadvocacy).

${ }^{31}$ Creada por Luder Fuentes en el 2007

${ }^{32}$ Es un grupo afiliado al partido colombiano de izquierda Polo Democrático Alternativo que reagrupa a los sectores, organizaciones y activistas LGBT

${ }^{33}$ El Polo Democrático Alternativo (o PDA) es un partido político colombiano de izquierda democrática, resultado de la unión del Polo Democrático Independiente (PDI), con el movimiento Alternativa Democrática. 
Aquí, realizaron acciones de liderazgo para la participación política como espacio para intervenir su situación de discriminación. También, aportan a este proceso, como escenario para la socialización, solidaridad, encuentro y reflexión las discotecas y bares gays de la ciudad, las más conocidas, Sky, de Hemel Noreña, en la actualidad convertida en la Fundación Sky ${ }^{34}$; Estudio 54, de Fernando Palacio; Pascha, de Jimmy Varela; Baco y Troya, entre muchas. Todas estas expresiones se aúnan para la actual conformación de la Mesa de Organizaciones Sociales LGTB Barranquilla. En la actualidad existen una variedad de organizaciones en los municipios del Departamento por los derechos de la comunidad diversa.

Según Wilson Castañeda, existen tres hechos iniciales del movimiento en Barranquilla y el Departamento: En el primero, se aglutinan, la participación política de la comunidad LGTBI promovida por el Polo Democrático, a través del Polo de Rosa, la agenda a nivel nacional sobre la epidemia del VIH/SIDA y la resistencia homofobia heterosexual sobre la comunidad. Estos sucesos generaron la visibilización y la movilización de los activistas por sus derechos humanos en el Departamento. El segundo, el Manual de Policía Departamental ${ }^{35}$ y la violencia sistemática policiva sobre la comunidad de diversidad sexual que se ubica en la calle 70 y Carrera $38^{36}$ y tercero, la creación de la Mesa de Organizaciones Sociales LGTB Barranquilla, para la incidencia de visibilización y defensa de los derechos de lesbianas, gays, transexual, bisexuales e intersexual. Según la dirigencia de diversidad sexual, estas acciones se facilitan con los aportes económicos que hacen las discotecas gays y la contribución que reciben de la incidencia política y el avocacy a las entidades públicas y los organismos internacionales.

${ }^{34}$ Fundación que trabaja por la igualdad de derechos y la inclusión de las poblaciones vulnerables de Barranquilla y el Atlántico.

${ }^{35}$ El Artículo 66 de la Ordenanza 0018 de 2004 que reglamenta el Manual de Convivencia Ciudadana del departamento del Atlántico y estructura el código de policía del mismo departamento, señalan que la población LGBTI debe abstenerse a provocar e incitar a otras personas y evitar la exhibición y comportamientos no normatizados. Esto artículo es aún vigente, aunque se establecieron modificaciones del reconocimiento de los derechos de esa comunidad en el Artículo 55 del mismo Manual.

36 En estos sitios públicos de la ciudad de Barranquilla la diversidad sexual se concentra en las horas nocturnas, generalmente para ofrecer los servicios sexuales. Donde suele ser retirados por agentes del orden público. 
En la actualidad la diversidad sexual es visible y reconocida en el Departamento a través de las acciones de hecho y derecho, tales como las gestiones que realizan ante los entes gubernamentales, plantones y marchas. En todas estas organizaciones son más perceptibles los hombres en la dirigencia y el activismo que las mujeres, ellas son escasas y con poca presencia en este movimiento en lo local, dado a que esta es la forma como la cultura de dominación masculina expresa la división social de los roles tradicionales del binomio masculino/femenino, tanto del ejercicio del poder y del espacio público, por tal razón, el poder y lo público es para los hombres y la subordinación y lo privado para las mujeres. Esta relación no excluye a lesbianas y mujeres tras y bisexuales en el movimiento LGTBI. Bourdieu (2004) afirma: que la sociedad les reconoce preferencia universal a los hombres a través de las estructuras sociales y de las actividades productivas y reproducción biológica.

No obstante, a la escasa participación de mujeres en el movimiento LGTBI, la existencia de los grupos en el Departamento son avances significativos para la interlocución del movimiento con el Estado y ganar consenso social. Aunque, es un proceso que requiere de mayor articulación de los grupos entre sí, menos personalismo centrados en una sola persona, en el interés individual o únicamente grupal o de su organización; se debe extender más la vinculación de la dirigencia con la base de la comunidad de diversidad sexual departamental y deben mejorar la articulación de las demandas específicas LGTBI con el resto del movimiento social, que reclama garantías sociales, e igualmente, con los entes gubernamentales locales y nacionales.

De forma, se puede ampliar y fortalecer la agenda para la consolidación de los derechos humanos desde lo local y con mayor impacto regional y nacional. Además, es una dirigencia empoderada más desde la acción pública, pero con escasa formación teórica que permita trascender la sola acción y que puedan presentar elementos conceptuales a sus necesidades concretas y así, logren una mejor articulación e intervención con los sectores estatales comprometidos con sus derechos humanos y los otros sectores sociales. 


\section{Metodología}

El objetivo del artículo es describir el autoreconocimiento y el empoderamiento juvenil de la diversidad sexual universitaria del Departamento del Atlántico por sus derechos humanos en los centros de educación superior donde realizan sus carreras profesionales. Se utilizó el método descriptivo y cualicuantitativo con un enfoque etnográfico. Las técnicas de investigación son: revisión bibliográfica, observación participante, encuestas estructuradas (20) y entrevistas semiestructuradas (12) a universitarios: Universidad del Atlántico, Universidad del Norte y Uac-Pride, total 32 gays, lesbianas, transexuales y bisexuales, seleccionados al azar en el ciclo de edad de 16 a 28 años de edad; de diferentes niveles socioeconómicos (1-6) y programas profesionales pertenecientes a los tres grupos universitarios de diversidad sexual. Igualmente, se entrevistaron a 8 dirigentes del movimiento LGTB del Departamento del Atlántico, en total para el presente Artículo se entrevistaron y encuestaron 40 personas, las cuales fueron realizadas en el 2017. De esta forma, se construyó y contextualizó la pregunta problema: $¿$ Cuál ha sido el empoderamiento personal y colectivo estudiantil universitaria de diversidad sexual en del Departamento del Atlántico?

\section{Movimiento universitario de diversidad sexual}

Con la incidencia de las acciones individuales y colectivas, convertidas en movimiento social, estas formas organizativas se involucran en los nuevos movimientos sociales, los cuales son una estrategia para la defensa de la calidad de vida de la población que la integra. Giddens (2000), define: al Movimiento Social como la forma de lucha colectiva de la población por el interés común. Desde este concepto, la diversidad sexual aglomera su interés común en el movimiento, el cual les ha permitido incluir el tema LGTBI en la escena pública, en la exigibilidad de derechos y en la reflexión académica e investigativa, posibilitándose así, la visibilización y la sensibilización de su existencia como parte de la cotidianidad. A la par, se masifica el autoreconocimiento y empoderamiento de lesbianas, gays, transexuales y bisexuales quienes asumen sin reservas la orientación sexual, que les indica el sentir erótico de su cuerpo asexuado. De este modo, el hecho adquiera responsabilidad estatal y social. Fausto-Sterling (2006) afirma que "solo nuestra concepción de género, y no la ciencia, puede definir nuestro sexo” 
(p. 17). Además, expresa, Coleman (1971) (Citado por Fausto-Sterling, 2006) que los cuerpos son asexuados y son ambiguos.

Bajo este prisma reivindicativo de derechos para lesbianas, gays, bisexuales y transexuales, la juventud estudiantil de diversidad sexual de la Universidad del Atlántico, la Universidad del Norte y la Universidad Autónoma del Caribe asumen la auto reflexión de la situación excluyente que viven en esos centros de educación superior y deciden organizarse como una forma para evitar la exclusión social por su disidencia sexual. Para organizarse contaron con el apoyo de la red de amistades heterosexuales, instancias administrativas y algún personal docente en cada una de esas entidades de educación superior.

De esta forma, se convirtieron en grupos estudiantiles universitarios denominados: Uniatlántico Diverso, Uninorte Diverso UAC-Pride; los tres asumieron la identificación institucional de cada uno de sus centros educativos y colocándole el interés común que los aglutina que es lo diverso como una forma de sentido de pertenecía corporativa y al mismo tiempo de compromiso con la institución para la inclusión. Por su parte, el grupo de Uniautónoma, según su dirigencia, le unen a la sigla de la universidad la palabra Pride, que es sinónimo de orgullo e igualmente, construye de allí, el siguiente acróstico con ese vocablo: con la $\mathrm{P}$, permeancia y participación; la $\mathrm{R}$, respeto; la I, integración, $\mathrm{D}$, derechos y la $\mathrm{E}$, educación. Todo ello involucrado con el lema: "Con la educación e investigación trabajamos desde la academia para la sociedad".

Los tres grupos estudiantiles: Uniatlántico Diverso, Uninorte Diverso y UAC-Pride viven su identidad sexual en forma abierta o encubierta. Según los resultados de las encuestas son una población joven, están en el ciclo de edad de 16 a 28 años; ubicados en todos los niveles socioeconómicos $(1-6)^{37}$; perteneciente a los distintos tipos de familia que integran el Departamento, en donde han sido socializados en ambientes familiares más sanos y regulares que violentos. En su seno familiar el $67.8 \%$ saben de

\footnotetext{
${ }^{37}$ Legalmente existen seis niveles socioeconómicos. El nivel más bajo es 1 y el más alto es 6. De acuerdo al Departamento Administrativo Nacional de Estadísticas (DANE) en la encuesta de Calidad de Vida de 2003 citado en el documento CONPES 3386 del 2006.
} 
su condición sexual, el $17.8 \%$ no saben, $10.7 \%$ no sabe si su familia sabe y $3.5 \%$ no contestó. Aunque, el $72.7 \%$ aún lo oculta en lo público, mientras que el $27.2 \%$ no la oculta. Quienes lo oculta lo utilizan como estrategia para evitar la exclusión y el retiro del apoyo económico y afectivo de sus familias, en razón a que aún tienen dependencia económica familiar y no saben qué actitud tendría su familia al conocer su homosexualidad y temen que les puedan retirar el apoyo económico. Esto lo señala Viñueles (2006), cuando afirma: que la reacción de la familia es distinta y puede ir de la aceptación al rechazo total o parcial, e incluso puede incluir el retiro abrupto del seno familiar.

Los resultados de la investigación señalan que el tipo de familia, el ambiente familiar y convivencia con la presencia o ausencia de la figura masculina o femenina tiene poca o ninguna incidencia para definir una identidad sexual diversa, tal como tradicionalmente suele pensarse. En este hecho confluyen la existencia de un sin número de factores biológicos y sociales que lo proporcionan. FaustoSterling (2006), afirma: que la homosexualidad está en correspondencia a una tendencia orgánica que se puede librarse en un ambiente social que la facilita.

La comunidad de diversidad sexual en estudio puede identificar su sexualidad disidente en cualquier etapa de su vida: niñez, pubertad, adolescencia y juventud. El ciclo con mayor porcentaje de la identidad sexual es en la pubertad y adolescencia, en razón a que esta es la etapa donde se despierta el mayor interés por la necesidad erótica. Cuando identifican su homosexualidad mayormente lo comunican a las amistades, seguidas por algunas personas de la familia: mamá, hermano (a), primo (a) y padre. La actitud que tiene la persona a quien se le confía su no heteronormatividad es generalmente de apoyo y pocas veces de rechazo. La identificación sexual de gays, lesbiana, bisexual, transexual les genera un cumulo de inquietudes que alteran su estabilidad emocional en lo individual y colectivo, que pueden expresarse en: miedo; vergüenza; asombro; indiferencia; rechazo y tristeza. Estos estados suelen generales situaciones depresivas leves, moderados o agudos, aunque, están quienes no se alteran y viven una vida equilibrado con su no heterosexualidad. 
Esta población establece relaciones de parejas similares a las heterosexuales, algunas son duraderas y otras son efímeras. Las personas diversas más tradicionales se identifican como pasivas, activas y versátil o diversa o cincuenta y cincuenta ${ }^{38}$. Cantillo (2016) manifiesta: "otros no desarrollan ningún tipo de división, solo se dejan guiar por la creatividad y el deseo que les imponen sus emociones eróticas" (p.100). Tienen los problemas propios de las relaciones humanas eróticas: celos, violencias, inestabilidad económica e indiferencia o ausencia afectiva, entre otras. Algunas relaciones de parejas son equilibras y armoniosas, expresan que viven una sexualidad donde explorar todo el sentir sexual de sus cuerpos, lo cual las lleva a tener una sexualidad plena y sin diferencia.

Estos grupos universitarios en estudio pertenecen a los programas académicos que ofrecen sus centros educativos (ingenierías, ciencias, humanas, sociales, ciencias básicas, comunicación social, arquitectura, derecho, contaduría y salud), en el caso de la Uniautónoma participa población egresada. Los resultados de la investigación señalan que tienden a escoger la carrera profesional con el estigma tradicional de los roles de género, del binarismo que separan el hacer y pensar de hombres y mujeres. Unos relacionados con el cuidado y otros fuera del cuidado. Además, esta división intervine en la forma como las profesiones que tienen el mejor posicionamiento y status en el mercado laboral.

Los grupos estudiantiles universitarios, Uniatlántico Diverso, Uninorte Diverso y UAC-Pride, surgen como una alternativa para encontrar espacios de inclusión para la reflexión académica, investigativa y de proyección social para el reconocimiento de derechos, respeto, tolerancia y equidad de las personas que se autoidentifican con orientación sexual de lesbianas, gays, bisexuales y transexuales en cada uno de esos centros de educación superior en el Departamento del Atlántico.

${ }^{38}$ Lo activo hace relación al hombre que penetra, pasivo a quien se deja penetrar y versátil o cincuenta y cincuenta cuando ambos cumplen las funciones penetrar y dejarse penetrar. 
La iniciativa de la organización estudiantiles universitarios sobre la defensa de diversidad sexual surge en las universidades del centro del país ${ }^{39}$. La primera en la Región Caribe y el Departamento del Atlántico es la de la Universidad del Norte (febrero de 2012), denominada Uninorte Diverso. Según las personas entrevistadas, el grupo se inicia cuando un promedio de cincos estudiantes, mayormente hombres, identificaron la ausencia del tema de diversidad sexual al interior de la misma universidad y, además, cuando solicitaban la información del tema en internet los computadores se bloqueaban. Frente al hecho se reúnen y deciden crear un grupo estudiantil que promocionará el reconocimiento e inclusión de los derechos de lesbianas, gays, transexuales y bisexuales en la Uninorte. De esta forma, se ampliaría la reflexión sobre el tema de diversidad que contribuyera a crear una cultura de tolerancia al interior y exterior de la Universidad del Norte. Una vez, el grupo se organizan internamente gestionan su formalización ante el ente institucional encargado del Bienestar Universitario en dicha Universidad, y de esta forma se oficializa como grupo estudiantil Uninorteño e inician sus acciones de reconocimiento y proyección social. (Integrante del grupo estudiantil Uninorte Diverso2).

Esta iniciativa reivindicativa de la diversidad sexual es acogida al interior de la Universidad. Esto se facilita a nivel externo, por las aperturas sociales y jurídicas que se legislan desde lo internacional y nacional sobre el tema y a nivel interno, el rector de la misma, había solicitado que el personal docente y administrativo no realizará el señalamiento excluyente a esa población. Un dirigente del grupo estudiantil afirma: el rector, doctor Ferro Bayona, solicitó, a través de un correo de internet, a toda la comunidad vinculada a la Universidad que no discriminaran a las personas con orientación sexual distinta a la heterosexual, con el fin de evitar que en ese centro de educación superior se manifestara cualquier tipo de fobias por parte de los estamentos universitarios.

${ }^{39}$ Universidad Nacional de Bogotá (1995) fue creado por un grupo de estudiantes de la Nacional el Grupo de Apoyo y Estudio de la Diversidad de Orientación Sexual GAEDS, con el apoyo de la Vice-decanatura de Bienestar Universitario y la Facultad de Ciencias Humanas. Y en la Universidad de los Andes (1996) el Grupo de apoyo a la Diversidad de la Orientación Sexual, GADOS, ambos agrupaban hombres y mujeres. 
Igualmente, en algunos de los programas académicos de la universidad, profesores por interés personal, abordaban el tema. Esto fue la plataforma para que el grupo estudiantil se instalara y desarrollara internamente con el apoyo de la comunidad estudiantil de orientación sexual homosexual y heterosexual, algunos académicos y las instancias administrativas, en especial, Bienestar Universitario. En la actualidad el grupo estudiantil está integrado en promedio por 47 personas, 25 mujeres y 22 hombres, con orientación sexual, gays, lesbianas y bisexuales y realizan las acciones que les han permitido posesionar el tema desde los derechos humanos. (Integrante del grupo estudiantil Uninorte Diverso 3).

Entre las acciones realizadas por el grupo estudiantil están: foros y seminarios de reflexión académica; cines foros; jornadas de capacitación y obras de teatro, entre otras. Todo relacionado con el tema LGTB, como una estrategia para visibilizarlo, sensibilizar y posibilitar que se incluya como parte de la cotidianidad y evitar las fobias existentes en los distintos espacios de la vida académica de ese centro educación superior. Además, realizaron formalmente un matrimonio igualitario simbólico, el cual fue promocionado por los medios de comunicación local como real, aunque, a la opinión pública se le explicó que el acto era solo simbólico y educativo.

Por su parte, Uniatlántico Diverso surge de la iniciativa de un promedio de cinco estudiantes heterosexuales y homosexuales sensibilizados e interesados en debatir el tema de los derechos humanos de las personas de diversidad sexual en el contexto de la Universidad del Atlántico y en el espacio local. Buscaban transformar los imaginarios y prácticas culturales estigmatizantés a la comunidad diversa y de esta manera, facilitar la promoción, la organización y la participación política universitaria. Además, de la incidencia que generó la creación del grupo de la Uninorte, con el cual la comunidad diversa uniatlanticense tenía relaciones.

La iniciativa al interior de la Universidad del Atlántico tiene varios antecedentes. La existencia de una variedad de organismos y hechos relacionados con la equidad de género y mujer a través del Grupo de investigación Mujer, Género y Cultura; Centro de Documentación Meira Delmar; semillero de investigación Mujer, Género y Cultura; la electiva de contexto Género y Diversidad Sexual, electivas de profundización en los Programas 
de Sociología, Filosofía, Economía y Derecho y las Cátedras de género. Desde estas instancias y en particular, con la electiva de contexto Género y Diversidad Sexual, convertido en el primer espacio académico que abordó abiertamente el tema de diversidad sexual al interior de la universidad, a través del cual se realizan acciones específicas de reflexión académica, investigativa y de proyección sobre el tema ${ }^{40}$, estos hechos se convirtieron en la plataforma al interior de la institución para el surgimiento y posicionamiento del grupo estudiantil Uniatlántico Diverso.

Desde la electiva de Contexto y el Centro de Documentación Meira Delmar se desarrollan diversas actividades formativas, culturales y de acción conjunta con la dirigencia del movimiento de diversidad sexual y las entidades públicas locales ${ }^{41}$. Además, a través del acercamiento establecido con Uninorte Diverso se crea en el 2013 el grupo estudiantil Uniatlántico Diverso, siendo reconocido como grupo estudiantil de la Universidad Atlántico por el ente que atiende el Bienestar de los estudiantes en la misma universidad. En la actualidad, el grupo estudiantil está integrado en promedio por 15 activistas: 10 hombres y 5 mujeres.

UniAtlántico Diverso pretende ser un punto de inclusión de todas las instancias universitarias. Buscando desarrollar actividades pedagógicas, promover la tolerancia, la convivencia sana, la inclusión de derechos y la aceptación de la diversidad sexual en todas las instancias universitarias. Además, que lesbianas, gays, bisexuales y transexuales auto reconozcan su ruptura heteronormativa en su cotidianidad de la vida y sin ningún tipo de tabú, culpa y estigma, y para que se autoreconozcan en la disidencia sin miedo a la exclusión.

${ }^{40}$ La asignatura fue promovida y realizada por la autora del presente artículo. Se ofreció al inicio con cierto temor pensándose que no sería acogida por la población estudiantil, sin embargo, tuvo y aún sigue teniendo buena receptividad tanto por parte, de los y las estudiantes heterosexuales como homosexuales. Esta asignatura fue reconocida por la Alta Consejería Presidencial para la Mujer y Asuntos de Género de la Presidencia de la Republica como parte de las buenas prácticas de género y diversidad sexual que realiza la Universidad del Atlántico.

${ }^{41}$ A través de la asignatura los estudiantes interlocutan con la directiva de la población LGTBI local, en conferencias, foros, charlas y otros. 
El grupo estudiantil UniAtlántico Diverso al interior de la Universidad realiza varias actividades de capacitación, reflexión académica y cultural como: cines foros, murales y campañas de VIH/SIDA, entre otras. Además, se vincula a las acciones nacionales y locales que promociona el movimiento de diversidad sexual como: Cine Rosa, Día de la no Homofobia y la Semana de la Diversidad. De esta forma, visibilizan y ubican el tema al interior de la universidad y lo local.

Por su parte, el grupo UAC-Pride, surge al interior de la Universidad Autónoma promovida por la comunidad estudiantil, administrativos y egresada interesadas en posicionar los derechos de la población diversas al interior del centro educativo y de la necesidad de tener un espacio para la investigación sobre diversidad con enfoque diferencial para atender sus necesidades. Fue creado en mayo del 2017, cuenta con una población de 10 personas, masculina y femenina. Inicialmente, existieron limitaciones para la creación, pero en la actualidad está reconocida por la universidad como un grupo estudiantil (Integrante del grupo estudiantil UAC-Pride4).

Entre las actividades que realizan están campañas de concientización, de respeto, tolerancia y visibilización por el reconocimiento de la comunidad diversa al interior de la universidad. Formación y capacitación sobre educación sexual, derechos humanos, identidad de género y diversidad sexual para la autonomía institucional para que se autoreconozcan como sujetos de derecho en la diversidad.

El grupo al interior de la universidad goza de un ambiente de diálogo interuniversitario y de ellos y ellas con la administración, lo que permite la visibilización del tema y las acciones a su interior con proyección al exterior.

Los tres grupos estudiantiles coinciden en el objetivo por los derechos de la diversidad sexual universitarios y juvenil que busca su inclusión en las instancias universitaria y con proyección social. En este sentido, su origen y las acciones que realizan son similares, así, que se relacionan con la plataforma nacional y local del movimiento social LGTBI que existe en el Departamento. Además, han establecido redes de accionar conjunto, lo cual fortalece y masifica la visibilización, sensibilización e inclusión del tema al interior y exterior de esos centros educativos. Asumen las activida- 
des académicas como espacio para la formación y educación sobre el tema y como estrategia válida para el autoreconocimiento, reconocimiento, respeto y proyección de los derechos de lesbianas, gays, transexuales y bisexuales en las Universidades del Departamento y el país.

El accionar interno en las universidades en estudio se favorece con el apoyo logístico y económico de las instancias universitarias sensibles con la diversidad sexual en cada una esas entidades, en particular, el ente relacionado con el bienestar y el desarrollo estudiantil. Además, algunos estudiantes y docentes heterosexuales afines con la causa de la comunidad LGTB. Sin desconocer, que, en esos mismos centros de educación superior, aún los estigmas de exclusión sobre la población permanecen y circulan en algunas personas, donde hay quienes todavía manifiestan su homofobia. De esta manera, se puede afirmar, que para masificar la inclusión de la diversidad sexual al interior de la vida cotidiana universitaria se requiere de procesos en el tiempo para lograr que se transforme esa situación en aperturas más incluyentes. La exclusión se convierte en limitante para el desarrollo pleno del operar por la defensa de los derechos humanos de esta población en el seno de esas instituciones universitarias.

A partir de la reflexión se puede señalar que los grupos estudiantiles de diversidad sexual en el Departamento del Atlántico con sus actividades organizativas, participativas e intervención social como jóvenes por la defensa de sus derechos humanos han logrado sesto procesos de acción significativa para la inclusión de la diversidad sexual en el entramado social. El primero, autoreconocimiento y empoderamiento individual. Segundo, jalonaron reconocimiento e inclusión del tema en las instancias universitarias. Tercero, crearon organización para la participación y movilidad social desde la disidencia juvenil. Cuarto, empoderamiento individual y colectiva. Quinto, generaron proyección social a nivel local y nacional y sesto, establecieron una propuesta organizativa de red juvenil estudiantil ligada a las acciones del movimiento local y nacional.

El primero, en lo individual reconocieron, autoreconocieron y crearon confianza que como persona disidente no son una sola, sino que son muchas, facilitándoles capacitarse y formarse en la teoría y en la práctica sobre el tema de diversidad sexual, con lo cual generaron resistencia, em- 
poderamiento y resiliencia para asumir sujetos y sujetas de derecho en una sociedad que los y las excluye por el solo hecho de no ser heterosexuales. De este modo, han crearon y ejercido nuevos liderazgos juveniles estudiantiles y universitarios en el activismo como lesbianas, gays, bisexuales y transexuales, permitiéndoles perder el miedo a la exclusión y creciendo en lo personal, estudiantil y profesional en la disidencia, asumiendo su vida personal, familiar, universitaria y social en forma plena. En otras palabras, se sintieron y asumieron como "normales" y no como "anormales. Un activista gay de 24 años de UniAtlántico Diverso, así lo expresa, "UniAtlántico Diverso es un espacio en donde todos los que se sientan raros encuentran alli, una forma de sentirse cómodos y en compañia". (Integrante del grupo estudiantil UniAtlántico Diverso 5).

Segundo, internamente como grupo estudiantil juvenil han aprendido y reconocido la importancia del trabajo en equipo por la defensa de los derechos humanos; se han relacionado con personas, grupos activistas de distintos matices y han tenido aprendizajes conjuntos de la importancia de unirse entorno a los intereses comunes. Se han fortalecido y empoderado en lo colectivo; han fomentado el respeto y reconocimiento por las diferentes orientaciones de diversidad sexual, identidades y expresiones de género, facilitándose afianzar y animar la auto aceptación, la tolerancia y el acato por las diferencias, contribuyendo así, a evitar la endodiscriminación que suele darse al interior de esa comunidad. También, al abandonar colectivamente las aulas de clase para incursionar al activismo del espacio público, enfrentaron el miedo al estigma social que los discrimina, excluye y condena por ser homosexuales. Asimismo, la salida del aula de clase para enfrentar el activismo en forma colectiva en la escena pública, es un avance significativo para el ejercicio de la ciudanía plena en la disidencia y la intervención social en el escenario público, más aún, para una población juvenil que busca y requiere espacios de interlocución para evitar la violación de sus derechos, lo cual es significativo en un país involucrado en unos acuerdos de paz para la reconciliación nacional.

Tercero proceso, la apertura del tema al interior de esos centros educativos de educación superior en una región como el Caribe, tradicionalmente conservadora y con presencia de dominación masculina, en donde se han 
abiertos espacios académicos, investigativos y de proyección social al interior de sus universidades, donde el tema no era tratado abiertamente. Estos grupos universitarios por los derechos homosexuales han permitido posesionar el teme en las agendas de estas universidades como parte del hacer universitario en lo administrativo; reconociéndolo como grupo estudiantil universitario; generaron, además, el apoyo de algunos docentes y estudiantes heterosexuales, los cuales son llamados "heteroafectivos". Con la inclusión universitaria se ha posibilitado que muchas personas lesbianas, gays, bisexuales y transexuales vivan su vida universitaria plenamente desde la disidencia. Una lesbiana de 20 años, activista de Uninorte Diverso, señala, "que la participación del grupo estudiantil por la inclusión de la diversidad en la Universidad del Norte, cambia el estereotipo de perversidad que se tenía sobre esa población generando la ampliación de las redes de apoyo y afecto" (Integrante del grupo estudiantil Uninorte Diverso 6).

Cuarto, con el empoderamiento individual y colectivo a través de su organización, participación, articulación, movilización e incidencia lograron inclusión y reconocimiento en el movimiento social LGTBI, pero sin abandonar el aula de clases. Posibilitándoles salir como grupo juvenil universitario al espacio público para reclamarse, conjuntamente con los "mayores", sujetos y sujetas de derechos. Identificaron que desde la acción colectiva como movimiento juvenil su causa coincidía con el movimiento de LGTBI y se unieron como una estrategia para aprender, fortalecer, ganar experticias, hacerse más visibles y ampliar su causa reivindicativa para la acción pública desde lo local, pasando por lo regional y nacional e incluso insertarse en lo internacional.

Se requiere que la dirigencia de estos grupos estudiantiles generen semilleros de formación al interior de la base universitaria para que las acciones de los mismos no se esfumen en el tiempo, cuando la dirigencia actual culmine sus carreras profesionales. Igualmente, la instancia universitaria promotora del bienestar de la población estudiantil y las sensibles con el tema debe estar atenta para fortalecerlos y mantenerlos en el lapso. También, el movimiento LGTB local le toca seguir apoyándolos y fortaleciéndolos desde la base. Es decir, la tarea es seguir articulando la formación, organización, ampliando la base, generando nuevos liderazgos y fortaleciendo el grupo para evitar su decaimiento y desaparición en el tiempo. 
Cinco, al exterior han generado proyección social al ser incluidos por el movimiento LGTBI como grupo estudiantil universitario y juvenil de diversidad sexual para la acción pública y por la defensa de sus derechos humanos, tanto al interior y al exterior de los espacios universitarios. De esta manera, forman parte activa del accionar del movimiento local y regional, entre ellas, Mesa de Organizaciones Sociales LGTB Barranquilla y Caribe Afirmativo, entre otras y se vinculan a todas las acciones formativas, culturales, cabildeo y marchas que programan el movimiento LGTBI. También, incursionan con sus iniciativas en otras universidades promoviendo la creación de grupos universitarios, tecnológicos diversos, entre ellos, el Servicio Nacional de Aprendizaje, en donde en la regional Atlántico, se le violentaba los derechos a un transexual, los cuales fueron reestablecidos a través de la Sentencia T-363 de 2016.

La inclusión de estos grupos estudiantiles universitarios juveniles en la ciudad de Barranquilla y el Departamento del Atlántico han sido significativo en lo individual y colectivo para el grupo estudiantil y el movimiento social LGTBI. Para ello, han contado con una variedad de aportes y apoyo institucional y personal para su creación y fortalecimiento. No obstante, la acción colectiva tiene aún limitaciones por parte de personas e instituciones. Entre las individuales se identifica el impedimento que tienen algunas personas de la comunidad juvenil estudiantil de diversidad sexual con capacidad de liderazgo y deseo de ejércelo, pero no lo pueden realizar públicamente por evitar el cuestionamiento familiar y social. Desde lo institucional, aún existen instituciones públicas y privadas donde algunas personas de su personal administrativo y el resto de la comunidad universitaria tienen resistencia para apoyar el tema de diversidad sexual, de ello no escapan las universidades en referencias.

Dado a que aún persiste, en el hilar del imaginario social la resistencia sobre la inclusión de los derechos humanos para la diversidad sexual en lo nacional y local. Esto es el resultado de una cultura patriarcal y judeocristiana que establece la condición binaria masculino/femenino instituyendo lo erótico afectivo en el marco de lo heterosexual. Convirtiendo la sexualidad en una forma de control social, que se construye, habitúa y trasmite en el proceso de socialización como algo inmodificable. Rubin (1986), afirma que sexo/género es el conjunto de disposiciones por el que una sociedad 
transforma la sexualidad biológica en producto de la actividad humana transformada. Desde esta perspectiva, socialmente, se legitima la heterosexualidad como el único modelo a seguir del erotismo y todo lo que este por fuera de lo heterosexual se asume como "anormal" y se estigmatiza.

Finalmente, el sexto, han creado una organización denominada Red de grupo universitario de diversidad sexual del Caribe como espacio de apoyo, trabajo, solidaridad, sororidad, afecto, crecimiento personal y organizativo. De esta forma, han construidos fuertes lazos de amistad personal y universitaria, autoreconocimiento individual, familiar y social para enfrentar los estigmas discriminatorios y excluyentes de que son objetos por la no ser heterosexuales. Esta red es clave para la organización, movilización y la incidencia social y la política en las diversas instancias de la vida cotidiana para afirmar y fortalecer sus necesidades y derechos como un sector excluido en una sociedad que aún no acaba de reconocerlos y, por tanto, asumirlos como parte integral y normal de su engranaje social.

En este sentido, desde los avances que realizan estos grupos estudiantiles universitarios se requiere del compromiso de todos los sectores sociales y estatales para la inclusión de los derechos humanos a un sector de la población que es discriminado por no responder con el modelo heteronormativo. Esto en razón, a que la sociedad ha establecido las relaciones eróticas afectivas no alejadas de lo reproductivo. Por ello, la sexualidad humana demanda ser dimensionada desde la sexualidad plástica, identificada por Giddens como esas nuevas expresiones de sexualidad que surgen de los diversos procesos sociales e históricos que separan el erotismo y la reproducción, lo cual es coincidente con lo que se plasma en los derechos sexuales y reproductivo, como una sexualidad para el encuentro entre pares humanos, el placer, la satisfacción y retiradas de lo reproductivo, como una forma de encuentro personal consigo mismo desde el reconocimiento de la otredad. Giddens (2008) señala: que el "amor confluente" es una relación de igualdad de dar y recibir para encontrar la "relación pura" y la libertad como principio humano." Igualmente, Touraine (2000), afirma: que la sexualidad convoca a la persona a la liberación creadora de placer y felicidad. Es decir, es hacer de la sexualidad uno de los mejores actos para la realización humana sin los estigmas y tabúes impuestos por la cultura binaria tradicional de los roles 
masculino versus femenino dictaminada por la cultura patriarcal y judeocristiana que excluye, discrimina y separa los seres más desarrollados del planeta, hombre y mujer.

Es, en resumen, ubicar la sexualidad desde una mirada y una postura integradora del ser humanista en forma holística que exprese todas las connotaciones humanas y espirituales del ser social en la diversidad.

\section{Conclusiones}

La diversidad sexual ha estado presente en la historia de la humanidad. Aunque ignorada y discriminada e incluso castigada, confinada y hasta causal de muerte. Cada momento histórico la ha catalogado de distinta forma, de acuerdo a las dinámicas sociales de sus tiempos como aceptable, mala, pecaminosa, enfermedad, delito y perversa entre otros, pero los cambios democratizantés, el mundo globalizado y la exigibilidad de derechos de la población vulnerada han logrado su inclusión en las agendas gubernamentales y privadas en ámbito nacional e internacional.

En la actualidad, la diversidad sexual se ha convertido en el movimiento social a nivel internacional, nacional y local de mayor trascendencia del presente, logrando inclusión en los distintos sectores sociales, económicos, políticos y culturales para el ejercicio de su ciudanía plena como sujetos de derechos. Aunque, en lo local requieren ampliar su base y la articulación con las redes de todo el movimiento social para que incursionen en la defensa de todos los derechos humanos de la población.

Las experiencias de participación, movilización y organización de la población estudiantil de estas tres universidades son significativas para la inclusión de sus derechos humanos. La diversidad sexual aglutinada alrededor de los grupos Uniatlántico diverso, Uninorte diverso y UAC-Pride lograron asumirse como comunidad no heteronormativa, pero no "anormales”. Crearon confianza de sí en lo individual y colectivo empoderándose y generando nuevos liderazgos para incluirse como grupo estudiantil universitario al interior de sus centros educativos y trascendieron al espacio público. Son reconocidos por el movimiento LGTB local, regional y nacional, uniéndose a la acción pública en todas sus actividades. 
La sociedad en general y el Estado en particular, tienen la responsabilidad social de aglutinar todos sus esfuerzos técnicos y económicos para trasformar los estigmas que hacen de la diversidad sexual un grupo social discriminado y excluido por el solo hecho de salirse del modelo normativo de la heterosexualidad. Se requiere asumir que la sexualidad es tan variada con la misma sociedad que cada persona la siente y expresa en un cuerpo sexuado de distintas formas sin exclusión de ningún tipo por su disidencia sexual.

Se requiere de políticas sociales y políticas públicas amplias y masivas para que se direccioné de mejor forma y con mayor responsabilidad las acciones de los derechos humanos de esta población diversa.

Es necesario que la sociedad funde unas formas diferentes de interacción social entre los seres más evolucionados del planeta, varones y hembras, como base para la justicia social con igualdad de género y al acceso a todos los derechos humanos sin ningún tipo de exclusión y ni discriminación social. De esta manera, se hace posible que en el país se realice un nuevo pacto para la convivencia humana tal como está plasmado en los acuerdos de paz y reconciliación nacional.

Este pacto por la convivencia humana debe plasmarse en todos los espacios de la vida cotidiana y en particular, en los centros educativos donde se forman las nuevas generaciones como una forma de gestar la sociedad con justicia social, igualdad de género y sin inclusión de ningún tipo. 


\section{Referencias bibliográficas}

Bourdieu, P. (2004). "La Dominación Masculina". Barcelona: Editorial Anagrama.

Careaga, G. (2004). "Sexualidades Diversas: Aproximaciones para su análisis”. México: PUEG/UNAM.

Cantillo, L. (2013). "La población de lesbianas, gays, travestis, bisexuales e intersexuales (LGTBI) en el Departamento del Atlántico". En: Revista La Manzana de la Discordia.Vol. 8 No. 1 (23-35).

Cantillo, L. (2014). "Género y carnaval en Barranquilla". En: Revista Amauta. Vol. 12 No.24 (151-173).

Cantillo, L. (2016). "Alteridades de las masculinidades gay en el Departamento del Atlántico". En: Revista Justicia Juris. Vol. 12. No 2 (95-106).

Coleman, W (1971). Biology in the 19tb century: problems of form, function and trasformation. Nueva York: Wiley. En: FaustoSterling, A. (2006). "Cuerpos sexuados, La Política de género y la construcción de la sexualidad". [Traducido al español de de Sexing the Body. Gender Politics and the Construction of Sexuality] Santa Cruz de Tenerife: Editorial. Melusina.

FaustoSterling, A. (2006). "Cuerpos sexuados, La Política de género y la construcción de la sexualidad". [Traducido al español de Sexing the Body. Gender Politics and the Construction of Sexuality] Santa Cruz de Tenerife: Editorial. Melusina.

Giddens, A. (2000). “Sociología”. 3ra ed.rev. Madrid: Alianza Editorial S.A.

Giddens, A. (2008). "La transformación de la intimidad, sexualidad, amor, erotismo en las sociedades modernas". Madrid: Cátedra.

Lagarde, M. (2005). "Los cautiverios de las mujeres. Madresposas, monjas, putas, presas y locas". 4ta ed. México: UNAM. 
Panadero, M. (s.f). El día en que gais, lesbianas, transexuales y bisexuales dijeron ;basta! Los disturbios de Stonewall Inn. Unión Sindical de Madrid Región de CCOO. C/ Lope de Vega, 38. 5a planta, 28014 Madrid. Recuperado de: http://docpublicos.ccoo.es/cendoc/040656Disturbios StonewallArcoiris.pdf.

Rubin, G. (1986). "El tráfico de mujeres: Notas sobre la "economia politica" del sexo". Recuperado de: http://www.caladona.org/grups/uploads/2007/05/ El\%20trafico\%20de\%20mujeres2.pdf

Touraine, A. (2000). “¿Podemos vivir juntos? Iguales y Diferentes”. [Traducido al español de Pourrons-nous vivre ensamble? Égaux et différents] 2da. ed. México: Fondo de Cultura Económica.

Velandia M. (2007). "Historia del Movimiento Homosexual Colombiano desde sus origenes hasta la culminación del siglo XX, Una historia vista en primera persona". Recuperado de: manuelvelandiaautobiografiayArticulos. blogspot.com/.../historia-del-movimiento-hom

Vera-Gamboa, L. (1998). "Historia de la Sexualidad". En: Revista Biomédica. Vol. 9 No. 2 (116-121). Recuperado de: http://www.revbiomed.uady. $\mathrm{mx} / \mathrm{pdf} / \mathrm{rb} 98927 . \mathrm{pdf}$

Viñueles, O. (2006). “Identidades lésbicas".2da ed. Barcelona: Bellaterra.

Weeks, J. (1998). “Sexualidad”. México, D.F.: Paidós.

\section{Otras fuentes}

Wilson Castañeda. Director de Caribe Afirmativo 1. Entrevista realizada, junio 2017.

Integrante del grupo estudiantil Uninorte Diverso 2. Entrevista realizada, noviembre 2017.

Integrante del grupo estudiantil Uninorte Diverso 3. Entrevista realizada, diciembre 2017. 
Integrante del grupo estudiantil UAC-Pride4. Entrevista realizada, septiembre de 2017.

Integrante del grupo estudiantil UniAtlántico Diverso 5. Entrevista realizada, noviembre 2017.

Integrante del grupo estudiantil Uninorte Diverso 6. Entrevista realizada, diciembre de 2017. 